\title{
Análise de uma Exposição Científica e Proposta de Intervenção
}

Analysis of a Scientific Exposition and Proposal of Intervention

\author{
Adriano M. Stuchi \\ Departamento de Ciências Exatas e Tecnológicas \\ Universidade Estadual de Santa Cruz \\ Rod. Ilhéus-Itabuna km.16, 45650-000, Ilhéus, BA, Brasil \\ E-mail:stuchi@uesc.br<mailto:stuchi@uesc.br> \\ Norberto Cardoso Ferreira \\ Instituto de Física, Universidade de São Paulo \\ E-mail:norberto@if.usp.br<mailto:norberto@if.usp.br>
}

Recebido em 29 de novembro, 2002. Aceito em 23 de abril, 2003.

\begin{abstract}
A proposta desse trabalho é a de analisar e intervir numa exposição de termodinâmica da Estação Ciência. Recorremos à investigação da linguagem dos monitores da Estação Ciência na explicação dos experimentos para ajudar no aperfeiçoamento da exposição. Utilizamos e analisamos alguns instrumentos de avaliação do processo ensino-aprendizagem em Museus e Centros de Ciências fundamentados em Vigotski e em cálculos estatísticos. Os resultados dessa pesquisa levam à consideração de três aspectos fundamentais:

-A importância dos monitores numa exposição científica e seu contínuo treinamento;

-A necessidade de aprimoramento da exposição num processo de avaliação que busque melhores resultados de aprendizagem;

-Visitas escolares programadas aos Museus e Centros de Ciência podem ser um fator muito importante para aumentar o interesse de alunos pelas exposições e para tornar mais significativa a aprendizagem nesses ambientes.

The proposal of this work is to analyze and to intervene in an exposition of Thermodynamics of the Estação Ciência. We appeal to the inquiry of the language of the monitors of the Estação Ciência in the explanation of the experiments to help in the perfectioning of the exposition. We use and analyze some instruments of evaluation of the process teaching learning in Museums and Science Centers based on Vygotsky and statistical calculations. The results of this research lead to the consideration of three basic aspects:

- The importance of the monitors in a scientific exposition and its continuous training;

- The necessity of improvement of the exposition in an evaluation process that lead to better result of learning; - Student visits to Museums and Science Centers are a very important factor to forster the interest of pupils for the expositions and make the learning more significant in these environments.
\end{abstract}

\section{Introdução}

Em abril de 1997, logo após o inicio no programa de pós-graduação em Ensino de Ciências do IFUSP e da FEUSP, começamos um período de atividades na Estação Ciência (vide item 2) como monitor (Adriano) e orientador (Norberto). Durante alguns meses, observamos todas as exposições sobre física lá apresentadas. Depois de algum tempo, escolhemos a exposição sobre termodinâmica para desenvolver a pesquisa. A localização dos experimentos no $2^{\circ}$ piso da Estação Ciência, num ambiente mais tranqüilo, e uma certa afinidade com o tema motivaram essa escolha.

Notamos o interesse das pessoas pelos experimentos. A grande maioria dos visitantes da Estação Ciência prestava atenção na explicação dos monitores e fazia muitas perguntas. Numa dessas observações, analisamos melhor o discurso dos monitores durante as explicações. Percebe- mos que algumas expressões como "temperatura de determinada coisa" ou "agitação molecular em determinado material" eram usadas sem que os visitantes pudessem ver um termômetro ou um experimento que demonstrasse a Teoria Cinética dos Gases. A partir dessas primeiras observações, surgiu a idéia de intervir na exposição, produzindo materiais - novos experimentos e roteiros de explicação, por exemplo - que complementassem o trabalho dos monitores.

Iniciamos então uma pesquisa-piloto com a intenção de avaliar as respostas de alguns visitantes num questionário sobre termodinâmica antes e depois de assistirem à exposição, e coletar material para uma análise mais detalhada da explicação dos monitores. Escolhemos alunos de $7^{a}$ e $8^{a}$ séries do ensino fundamental e das três séries do ensino médio para participarem da pesquisa. Julgamos que seria mais fácil trabalhar com esse público devido à grande 
freqüência com que visitavam a Estação Ciência. Os alunos primeiramente responderam a um questionário, depois visitaram a exposição e, na seqüência, responderam às mesmas questões. Dessa forma buscamos subsídios para fundamentar a intervenção (item 4).

Apoiando-nos em resultados da pesquisa-piloto, organizamos uma nova exposição sobre termodinâmica e a apresentamos. A nova exposição foi realizada numa escola pública estadual no interior do Estado de São Paulo em maio de 2000 (ítem 5).

Os alunos que assistiram à exposição na escola estadual foram divididos em grupos para que participassem de atividades respondendo a questionários e sendo entrevistados. Buscamos com isso indicações que pudessem mostrar a influência da exposição em respostas ou atitudes. O referencial teórico foi fundamentado na teoria de Vigotski e o acesso a outros trabalhos da área foram importantes para fundamentar cada etapa dessa pesquisa.

Os resultados desse trabalho têm implicações tanto na programação da Estação Ciência como nas escolas. Procuramos mostrar que, em relação ao que existia na Estação Ciência na época da pesquisa-piloto, os monitores poderiam ser mais bem treinados e a exposição de termodinâmica aperfeiçoada em função da linguagem empregada nas explicações. Nas escolas, os professores podem usar exposições como complemento às aulas, melhorando a qualidade das mesmas e reforçando a aprendizagem com auxílio dos experimentos.

\section{A Estação Ciência}

\section{II.1- Apresentação geral}

O presente trabalho foi iniciado na Estação Ciência. A Estação Ciência é um centro de divulgação científica da Universidade de São Paulo, que opera em convênio com o Conselho Nacional de Desenvolvimento Científico e Tecnológico - CNPq.

O grupo de visitantes, em torno de 25.000 por mês, é formado por pessoas de todas as faixas etárias. O público escolar compreende aproximadamente $60 \%$ dos visitantes.

As exposições da Estação Ciência abrangem várias áreas do conhecimento, ocupando aproximadamente 4600 $\mathrm{m}^{2}$, divididos em três espaços denominados Plataforma Informática, Plataforma Tecnologia e Plataforma Ciência.

Além das Plataformas, há locais para exposições temporárias sobre temas variados.

A Estação Ciência também oferece cursos de extensão para o público em geral e de atualização para professores, exibições de filmes e vídeos, empréstimos de materiais para exposições, aulas, e eventos para contínua divulgação de temas científicos e culturais.

A equipe da Estação Ciência é formada por professores universitários, pesquisadores, técnicos, coordenadores de projetos, secretários, pessoal de manutenção, vigilantes e monitores.

O endereço eletrônico da Estação Ciência na Internet é: www.eciencia.usp.br .

\section{Considerações sobre o Tema e a Metodologia de Trabalho}

\section{III.1 Pesquisas em Museus e Centros de Ciências}

Nesta seção fazemos um resumo de dois trabalhos que versam sobre o tema Museus e Centros de Ciências. Buscamos com isso as bases para a criação de uma metodologia de trabalho. Escolhemos dois trabalhos entre tantos outros por acreditarmos que o ambiente e o objeto de estudo eram semelhantes aos nossos.

Visitas a exposições em Museus e Centros de Ciências levam à aprendizagem [Gaspar, 1993] [ASTC, 1990]. Mas como essa aprendizagem pode ser analisada? Muitos trabalhos sobre avaliação de exposições foram publicados nos últimos anos. A leitura crítica de alguns deles foi útil para o estudo de uma metodologia de trabalho voltada à análise de uma exposição científica.

No artigo de Minda Borun, Christine Massey e Tiiu Lutter [Borun, Massey e Lutter, 1993], a aprendizagem é entendida como um processo pelo qual concepções ingênuas ou espontâneas são substituídas por informações mais poderosas, capazes de explicar um número maior de fenômenos. Depois da passagem pelo ensino formal, os alunos têm dificuldade em aplicar os conceitos em situações fora da sala de aula. O ensino formal deve promover uma mudança conceitual de concepções menos elaboradas para as mais elaboradas, numa organização conceitual mais sofisticada.

A pesquisa, realizada no The Franklin Institute of Science Museum [Borun, Massey e Lutter, 1993], teve o objetivo de investigar se as exposições daquele museu poderiam operar uma mudança conceitual em seus visitantes. A investigação começou com entrevistas para a verificação das concepções iniciais das pessoas sobre conceitos de gravitação. Os entrevistados primeiramente assistiam às exposições do museu, e depois respondiam perguntas relativas aos experimentos e outras tais como: "O que é gravidade?"

Praticamente todas as respostas analisadas estavam erradas. Baseados nas respostas, os pesquisadores construíram experimentos para tentar corrigir o que chamaram de "concepções errôneas" sobre Gravitação. Os visitantes deveriam ler atentamente as etiquetas dos experimentos seguindo passo a passo as instruções e verificando as explicações sobre os fenômenos.

Novas entrevistas foram feitas e os resultados foram melhores que os das primeiras entrevistas, ou seja, a porcentagem de respostas erradas diminuiu. Concluiu-se então que as pessoas aprenderam melhor os fenômenos demonstrados por experimentos construídos especialmente para confrontar suas concepções errôneas sobre o assunto.

$\mathrm{O}$ que mais nos chamou a atenção nessa pesquisa foram os aspectos do tempo de interação e a maneira como os visitantes obtinham as informações. As pessoas observaram os experimentos por horas e liam as etiquetas para obter as explicações.

Mencionamos esses fatos porque, por experiência, sabemos que pouquíssimas pessoas liam as etiquetas dos experimentos da Estação Ciência, principalmente as crianças. Não lendo as etiquetas os visitantes se apegavam mais aos aspectos lúdicos dos experimentos sem voltar sua atenção para as explicações mais elaboradas cientificamente. Mesmo os 
que lêem as etiquetas atentamente muitas vezes não compreendem seu significado. Isso reforça a importância dos monitores acompanharem os visitantes numa exposição científica, dando explicações mais detalhadas e de linguagem simples. Quando os monitores não estão presentes, mesmo as pessoas mais atentas às etiquetas, não demoram mais que um minuto frente aos experimentos.

Faz-se necessário também pensar na linguagem como objeto de estudo numa exposição científica. Como nos mostra o artigo de Guaracira Gouvêa e Martha Marandino [Gouveia e Marandino, 1998] uma exposição, por mais completa e atraente que seja, abordando aspectos culturais, históricos, pedagógicos e científicos de um tema, pode não ser inteligível ao público se a linguagem com que é apresentada não for clara. A clareza da linguagem se faz pela conjugação dos aspectos visuais e dos modelos teóricos apresentados nas explicações.

Na Estação Ciência, na época da pesquisa-piloto, os monitores recebiam treinamento vez ou outra. Muitas vezes o que explicavam aos visitantes era o mesmo que ouviam de outro monitor mais experiente. Além disso, de modo geral, a exposição não se ajustava à linguagem dos monitores. $\mathrm{Na}$ maioria dos casos não se via num experimento, etiqueta ou painel o que era dito pelo monitor, isto é, apelava-se à imaginação em vez de observar a demonstração. Esses fatos comprometem a aprendizagem numa exposição de um Museu de Ciências.

\section{III.2 Museus e Centros de Ciências como instituições de ensino}

Fazemos abaixo um resumo do trabalho de Alberto Gaspar [Gaspar, 1993], para melhor compreensão do papel dos Museus e Centros de Ciências no cenário educacional, assim como a importância da teoria de Vigotski na conceituação do processo ensino-aprendizagem nesses ambientes.

Segundo esse trabalho, Museus e Centros de Ciência podem ser entendidos como instituições de educação informal. Isso porque, ao contrario da educação formal e não-formal, "a educação informal não obedece a currículos, não oferece graus ou diplomas, não tem caráter obrigatório de qualquer natureza e não se destina apenas a estudantes, mas ao público em geral. Estas são, basicamente, as características dos museus ou centros de ciências. Portanto museus e centros de ciências são instituições de educação informal" [Gaspar, 1993].

De acordo com Gaspar, a teoria socio-interacionista de Vigotski traz instrumentos e subsídios para a compreensão e análise do processo ensino-aprendizagem que se desenvolve em museus e centros de ciência.

$\mathrm{Na}$ teoria socio-interacionista de Vigotski enfatizam-se as interações sociais em relação à ocorrência do processo ensino-aprendizagem e um Museu de Ciências possui essas interações como principal característica. Na Estação Ciência, particularmente, as interações sociais ocorrem continuamente. Nota-se isso quando os monitores dialogam sobre determinado experimento com os visitantes ou um professor explica um fenômeno ao seu aluno, ou o pai troca conhecimentos com o filho.

De acordo com o trabalho de Gaspar, outra condição para que haja aprendizado num Museu de Ciência, segundo a teoria de Vigotski, é que o conteúdo temático das exposições possa atingir o nível cognitivo dos visitantes.
Pode-se acrescentar a esse conceito noções incorporadas à teoria de Vigotski por alguns de seus seguidores, como a definição de situação e mediação semiótica. Diferentes definições de situação em relação a uma visita podem ser observadas pelas diferentes maneiras com que os visitantes experimentam os objetos em exposição, e interagem com o monitor durante uma explicação. A mediação semiótica está relacionada à maneira como um monitor, professor, e visitante interagem verbalmente durante a apresentação de um experimento ou discussão de um fenômeno. É a forma como o monitor, o professor, o pai de família ou um colega de escola podem fazer com que um determinado conteúdo temático de uma exposição possa ser entendido pelos visitantes do Museu. No processo de mediação semiótica a linguagem é o veiculo que leva o conhecimento às pessoas. A linguagem se estrutura sobre os recursos que o monitor utiliza para uma explicação.

Uma outra indicação da teoria de Vigotski de como se dá o desenvolvimento cognitivo se refere à maneira como se desenvolvem os conceitos espontâneos ou científicos na criança. Em sua teoria, Vigotski afirma que esses conceitos se desenvolvem em sentidos opostos, dos níveis de maior complexidade para os de menor complexidade e viceversa. "É possível, assim, admitir-se que a ampliação do universo de conceitos de uma criança, sejam espontâneos ou científicos, proporciona uma intensificação desse processo de desenvolvimento" [Gaspar, 1993].

Sobre a aquisição de concepções errôneas em visitas a museus, segundo o modelo de desenvolvimento cognitivo de Vigotski, são irrelevantes possíveis preocupações sobre prejuízos que uma aprendizagem lúdica, uniforme, possa provocar, em relação ao desenvolvimento de conceitos na criança, sejam espontâneos ou científicos. De acordo com Gaspar, “(...) o processo de aquisição da ciência ou dos conceitos científicos é um processo cognitivo que, certamente, não se completa numa visita a um centro de ciências, como não se completa ao final de uma aula" [Gaspar, 1993].

Isso não significa, de modo algum, que se deva ter uma posição cômoda em relação ao ensino informal de ciências, partindo-se do princípio de que qualquer atividade seja válida. "Numa interação social dirigida à zona de desenvolvimento proximal de seus participantes, por exemplo, o monitor, professor, adulto ou parceiro mais capaz tem, implicitamente, um papel de orientação ou direção - é ele que tem a consciência do objetivo da tarefa, demonstração ou conceito que está sendo trabalhado" [Gaspar, 1993]. Como a situação, ponto de partida para a interação, é criada a partir da representação que cada um faz do objeto, é importante que sua definição seja aproximadamente a mesma para todos. Dessa forma a interação se torna viável e produtiva.

Partindo das afirmações feitas nessa seção, concluímos que os monitores ou professores têm papel fundamental numa exposição cientifica. $\mathrm{O}$ discurso de um monitor ou professor e sua linguagem deve ser consonante com o material da exposição, ou seja, com o que os visitantes estão observando. A linguagem das explicações tem o componente visual dos experimentos como aliado para que a exposição seja inteligível. São esses os elementos que buscamos na intervenção da exposição de termodinâmica da Estação Ciência e na reformulação do discurso dos monitores. 


\section{A Pesquisa-Piloto}

\section{IV.1- Metodologia de trabalho}

Nessa etapa da pesquisa, estudamos a exposição de termodinâmica da Estação Ciência em meados de 1998. Para isso fizemos uso de um questionário validado para avaliar as concepções científicas dos visitantes sobre os conceitos de calor, temperatura e energia interna [Silveira e Moreira, 1996]. Utilizamos o trabalho de Silveira e Moreira para elaborar seis questões do nosso teste, de um total de dez. As outras quatro questões se referem à dilatação, lei dos gases e transformação de energia, conceitos não abordados no questionário de Silveira e Moreira.

O nosso questionário foi aplicado pouco antes e imediatamente após a visita á exposição. As turmas que participaram da pesquisa foram conduzidas a uma sala onde respondiam o teste antes de ver a exposição. Depois da visita, os alunos retornavam à sala para responder ao mesmo teste.

A modificação feita no questionário de Silveira \& Moreira [Silveira e Moreira, 1996], que acreditamos não ter alterado a validade das questões, consistiu na escolha de 5 das 25 questões propostas e na modificação das alternativas de resposta.

Fizemos a pesquisa com grupos de 17 a 20 alunos de 7as. e 8as. séries do ensino fundamental, 1os. e 2os. anos do ensino médio, e uma turma do supletivo para o ensino médio.

O teste aplicado tinha 10 perguntas. Os alunos poderiam responder se as afirmações estavam certas, erradas ou se não sabiam a resposta.

A exposição visitada era formada pelos seguintes experimentos:

Anel de s'Gravezande (foto 1):

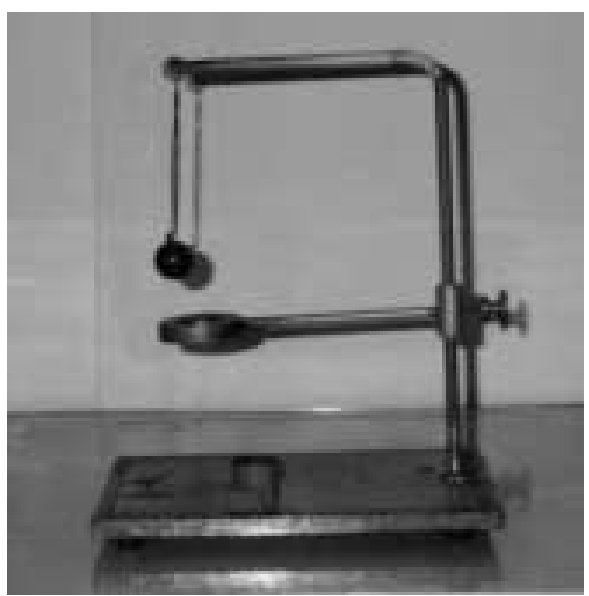

Ventoinha (para verificação da convecção) (foto 2):

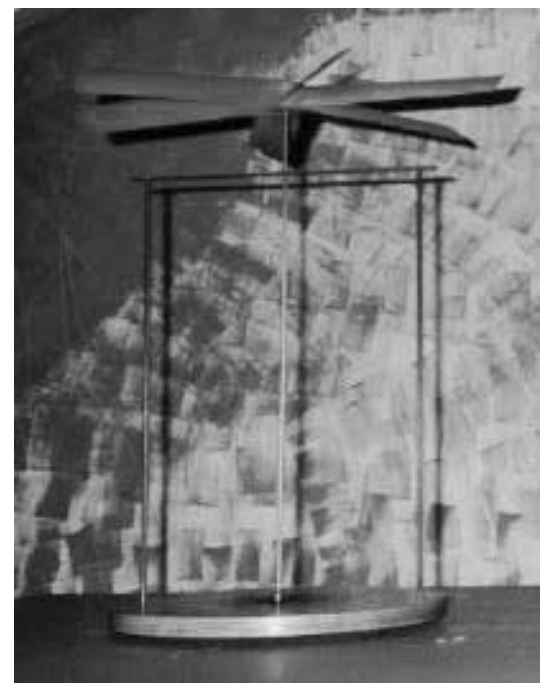

Eolípila de Herón (foto 3):

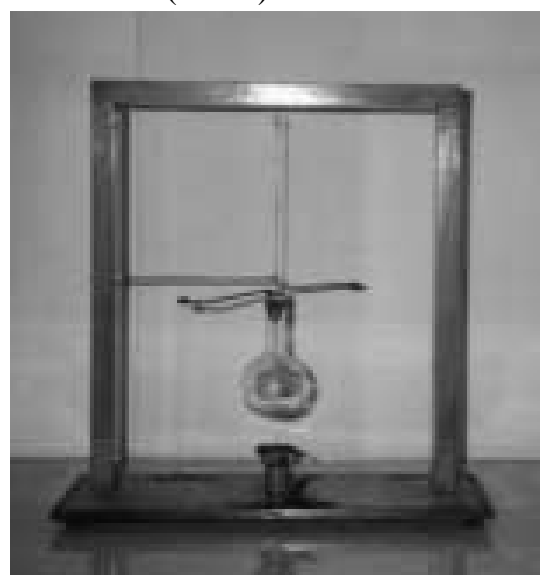

Protótipo de locomotiva (foto 4)

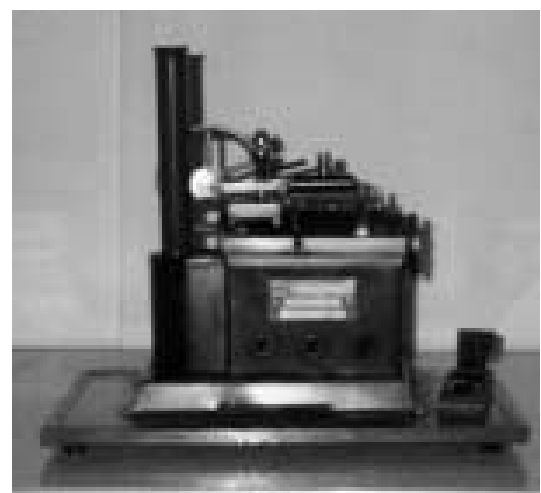

Termopares (foto 5): 


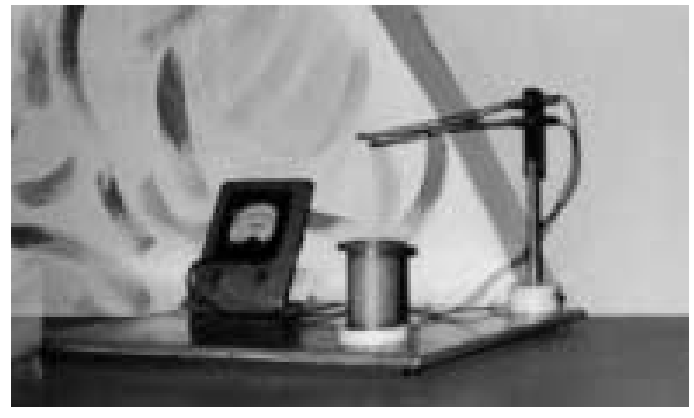

Experiência para a observação da teoria cinética dos gases (foto 6):

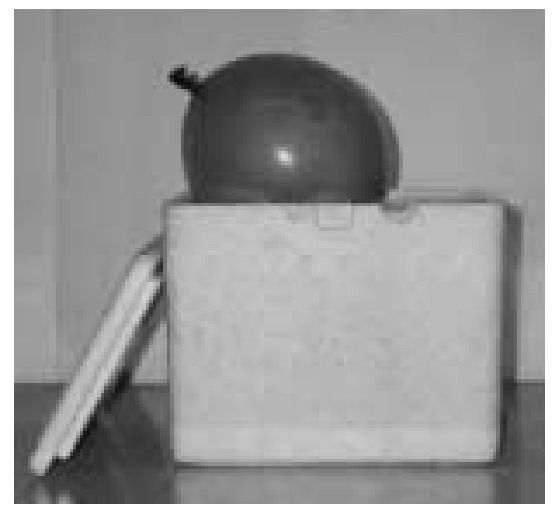

Células Fotovoltaicas (foto 7):

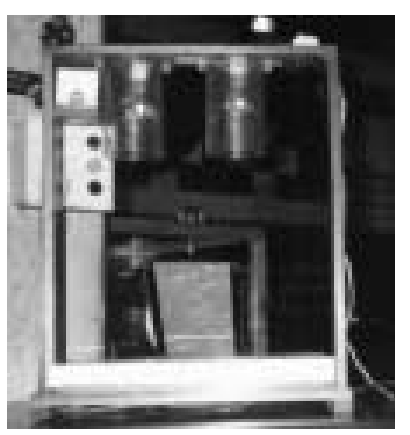

Os alunos foram acompanhados pelos monitores da Estação Ciência, que explicavam os experimentos sem qualquer intervenção do pesquisador. A fala dos monitores foi gravada e transcrita para análise.

\section{IV.2 Análise das respostas ao questionário}

Procedemos com cálculos estatísticos para obter respostas quanto à consistência das questões em relação aos objetivos delineados para o teste. A análise da consistência interna do questionário, estimado pelo coeficiente de fidedignidade, ou coeficiente alfa [Cronbach, 1951], se fez necessária como avaliação da confiabilidade do teste. Esses números foram interpretados como indicadores da eficiência do questionário em avaliar conhecimentos de termodinâmica. Foi uma forma de validar o teste para seus propósitos.
Com os cálculos percebemos que os coeficientes acusaram uma inconsistência do questionário.

\section{IV.3 Conclusão para a pesquisa-piloto}

Sendo o questionário fundamental para essa primeira abordagem aos alunos, concluímos então que houve falha na avaliação da exposição de termodinâmica. Ficou prejudicada a confiabilidade dos resultados que obtivemos até então, fazendo-se necessária outra investigação.

Uma das finalidades de uma nova pesquisa foi a de propor instrumentos de avaliação mais eficientes que os usados na abordagem apresentada acima.

Outro ponto seria a reformulação da exposição apresentada. Na transcrição das explicações do monitor observamos algumas falhas que poderiam ser corrigidas. A reformulação abrangeu os experimentos e a linguagem utilizada nas explicações.

\section{A Segunda Pesquisa e suas Implicações}

\section{V.1 A escolha dos experimentos}

A primeira pesquisa mostrou que a exposição ajuda os visitantes a entender alguns fenômenos em termodinâmica. Mesmo sem recorrer ao questionário, a observação de um dia de visitação foi o bastante para se concluir tal fato [ASTC, 1990].

Analisando o discurso de um monitor por meio de transcrições, notamos que alguns modelos usados nas explicações se tornaram muito abstratos. Concluímos que a inclusão de experimentos, ilustrações na forma de painéis ou instrumentos de medição, tal como um termômetro, tornariam os modelos mais concretos e significativos para quem assistisse a exposição. A partir dessas observações, surgiu a idéia de intervir no material dos experimentos expostos.

Nessa etapa da pesquisa, os experimentos da célula solar e dos termopares foram excluídos. Outro experimento excluído da exposição original foi a ventoinha para a verificação da convecção. Os demais experimentos da primeira pesquisa foram preservados. A nova exposição foi formada pelos cinco experimentos preservados da primeira etapa da pesquisa e mais dois inéditos.

Os tópicos abordados nos experimentos foram: dilatação, mudança de fase, transformações gasosas, transmissão de calor, transformação de energia e 1a. lei da termodinâmica.

Durante a exposição foram apresentados os seguintes experimentos, na ordem abaixo:

1) Modelo cinético dos gases I: a bexiga (foto 6); 2) Modelo cinético dos gases II: o pistão (foto 8); 3) Anel de s'Gravezande (foto 1); 4) Canecões de convecção (foto 9); 5) Eolípila de Herón (foto 3); 6) Locomotiva (foto 4).

Modelo cinético dos gases II: o pistão (foto 8): 


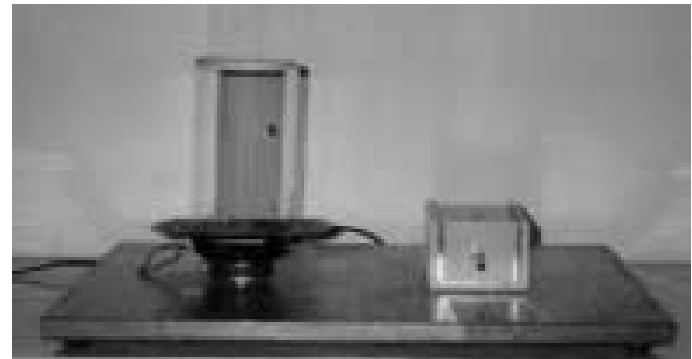

Canecões de convecção (foto 9):

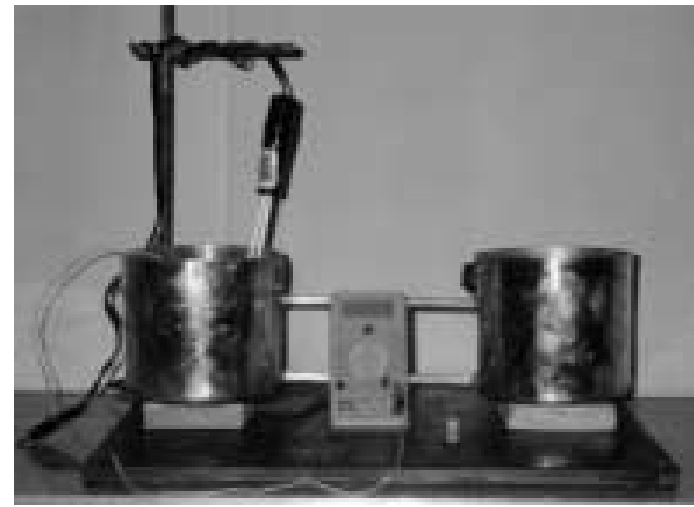

\section{V.2 Descrição dos experimentos}

1) Modelo cinético dos gases I: a bexiga;

O objetivo desse experimento foi demonstrar a variação do volume ocupado pelo ar dentro de uma bexiga em função da tempertatura.

Uma bexiga cheia de ar é colocada dentro de uma caixa de isopor com nitrogênio líquido (foto 6).

2) Modelo cinético dos gases II: o pistão:

Por meio deste experimento procuramos demonstrar o modelo para o comportamento microscópico de uma certa quantidade de gás dentro de um recipiente fechado. Procuramos demonstrar também o que acontece à pressão e volume do gás de acordo com variações da temperatura dentro do recipiente.

Ao ligarmos a fonte, o alto-falante começa a vibrar e impulsionar algumas miçangas de encontro a um êmbolo feito de cartolina (foto 8). O êmbolo então se move para cima.

3) Anel de s'Gravezande:

Uma pequena esfera de metal será colocada em contato com a chama de uma lamparina (foto 1), para que seja demonstrado o fenômeno da dilatação do metal com o aumento da temperatura.

4) Canecões de convecção:

Dois canecões de alumínio foram ligados por dois tubos também de alumínio, dispostos nas partes superiores e inferiores dos canecões (foto 9). Os canecões foram cheios de água e um ebulidor foi colocado no canecão à esquerda na foto 9 .
Com o experimento demonstrou-se que há troca de calor da água dentro dos canecões com o ebulidor por convecção e que a temperatura de ebulição da água é constante. O termômetro está disposto entre os dois canecões na foto 9.

5) Eolípila de Herón:

$\mathrm{O}$ balão de fundo redondo, que foi suspenso por um fio e cheio d'água, é rotativo (foto 3). Quando aquecido, a água entra em ebulição. $\mathrm{O}$ vapor que saia pelos caninhos acoplados ao balão fez o sistema girar.

Os objetivos deste experimento foram o de demonstrar como o calor pode se transformar em energia mecânica e dar uma referência histórica da primeira máquina a vapor construída pelo homem.

6) Locomotiva

Esse experimento é um protótipo de uma locomotiva (foto 4).

Demonstramos como o calor se transforma em trabalho e comentamos a importância histórica desta máquina a vapor.

\section{V.3 A investigação do processo ensino-aprendizagem numa exposição científica}

O conhecimento da ciência e seus métodos, leva ao desenvolvimento da consciência e ao domínio dos conceitos. "Ao operar com conceitos espontâneos, a criança não está consciente deles, pois sua atenção está sempre centrada no objeto ao qual o conceito se refere, nunca no ato do pensamento." [ Vigotski,1987]

A investigação da formação de conceitos científicos não pode se limitar à análise da reprodução verbal de um amontoado de palavras. A avaliação da definição verbal do conceito não traz conclusões objetivas sobre a aprendizagem. A formação de um conceito é parte viva de um processo intelectual em constante mutação.[Vigotski,1987]

A melhor análise obtém respostas em várias linguagens, pois o pensamento pode ser representado e esclarecido na fala, escrita ou por meio de instrumentos.

Uma avaliação completa deve explorar a diversidade de linguagens que podem vir a representar um pensamento. A linguagem se acumula em articulações para a formação de uma idéia que alcançam significado na elaboração de uma resposta.

A teoria cinética dos gases, por exemplo, é um modelo científico sobre o comportamento da matéria gasosa em circunstâncias especiais. Explicações sobre variações de pressão, volume e temperatura, além do comportamento das moléculas do gás em determinadas situações, fazem parte da linguagem científica empregada na explicação dos fenômenos físicos. A análise da utilização do modelo científico sobre os gases está centrada na investigação da linguagem por meio de avaliações. As respostas sobre as causas e consequiências de um fenômeno físico numa situação real, por exemplo, indicam o grau de compreensão do modelo científico relacionado. Questionários ou entrevistas são formas de avaliação dos resultados da exposição em função do aprendizado dos modelos científicos vinculados aos experimentos pelo professor ou monitor.

Um problema prático, inteiramente novo para o aluno, pode ser solucionado pela articulação da linguagem em função de um modelo científico. Um novo conceito, arti- 
culado pelo aluno, será colocado em prática para responder a pergunta do questionário. Analisando essa resposta podese verificar se o conceito espontâneo do aluno aproxima-se do modelo científico.

Tomando por base esses conceitos, as estratégias de avaliação foram centradas na linguagem utilizada nas respostas dadas. Os questionários se concentraram na linguagem escrita e as entrevistas nas linguagens oral e gestual.

\section{V.4 Estratégias de Avaliação}

A avaliação foi feita em três etapas. A primeira etapa se deu com a aplicação de questionários. Esperamos aproximadamente um mês para iniciar uma outra etapa. Começamos então uma série de entrevistas com alunos que participaram da exposição. O diálogo entre o entrevistador e os alunos teve o propósito de avaliar a formação de conceitos científicos a partir da exposição.

A última etapa de avaliação consistiu também numa entrevista iniciada aproximadamente seis meses depois de concluída a exposição. Nessa entrevista, alguns alunos foram colocados diante de um programa computacional para resolver uma situação-problema utilizando os modelos científicos de termodinâmica. O software mostrava aos alunos uma simulação sobre o Movimento Browniano, conteúdo estudado em termodinâmica. Os alunos deveriam descobrir as causas do Movimento Browniano, aplicando um dos modelos trabalhados durante a exposição de termodinâmica.

\section{V.5 Apresentação dos instrumentos para análise}

\section{V.5.1- Primeira etapa: os questionários}

Uma avaliação mais rigorosa do primeiro trabalho nos fez perceber que deveríamos mudar o questionário utilizado. Se o nosso objetivo era analisar o que os visitantes aprendem sobre a teoria cinética dos gases, por exemplo, julgamos que as respostas ao questionário deveriam indicar isso com maior clareza. A análise de questões abertas e dissertativas indicou com mais precisão o aprendizado, conduzindo a uma avaliação mais eficiente da exposição.

Aplicamos, primeiramente, um questionário com situações práticas ou do cotidiano dos alunos relacionadas ao conteúdo da exposição. Verificamos como os alunos solucionavam problemas práticos em que eles deveriam usar conceitos de termodinâmica. Analisamos a evolução das respostas após a visita à exposição com um questionário semelhante.

Se uma exposição despertar nos visitantes algum conhecimento que eles possam relacionar ao seu cotidiano, diremos então que ela está cumprindo com seus objetivos. Podemos medir a eficiência de uma exposição de acordo com a habilidade dos alunos em aplicar o que aprenderam em situações práticas.

Analisamos a evolução das respostas de cada aluno em questionários diferentes, aplicados antes e depois de passarem pela exposição.

Frente às considerações acima, podemos dizer que uma exposição científica pode estar relacionada ao cotidiano dos visitantes, ajudando a explicar através das demonstrações experimentais elementos do dia-a-dia sob a ótica de modelos científicos. Buscamos assim, na elaboração de novos experimentos para a exposição de termodinâmica da
Estação Ciência, uma possibilidade de facilitar aos alunos visitantes o entendimento de conceitos científicos, pela direta visualização de um fenômeno e relação deste com o cotidiano.

O questionário foi voltado à avaliação do enriquecimento cultural de quem assistiu à exposição. Dizemos isso não somente do ponto de vista da teoria científica, mas também pela relação que os alunos puderam fazer com assuntos de imediato interesse na vida cotidiana.

Este trabalho estudou a aprendizagem do conteúdo científico de uma exposição sobre termodinâmica sob determinados aspectos, a capacidade dos alunos em resolver problemas desencadeados por situações reais, dentro do contexto da exposição, ofereceu indicações de como os alunos de ensino médio utilizam o conhecimento científico da forma como foi apresentado.

As questões dissertativas apresentadas aos alunos mostraram respostas dadas em dois momentos: antes e depois da visita à exposição. A análise das respostas procurou apontar diferenças entre as respostas dadas em cada situação de acordo com a linguagem utilizada. Avaliamos erros e acertos em comparação com as respostas consideradas cientificamente corretas, detectando se o fato dos alunos terem assistido ou não à exposição poderia ter influenciado nas respostas.

Nessa etapa, os alunos responderam a um questionário sobre termodinâmica. Cada grupo de 40 alunos em sala de aula foi dividido em duas turmas. Enquanto a primeira turma assistia à exposição, os outros respondiam ao questionário. Na mesma semana, em outra aula de Física, os alunos que responderam ao questionário se dirigiam à exposição e vice-versa.

Foram elaborados dois questionários diferentes que abordaram os temas da exposição. Os questionários foram detalhadamente explicados antes de serem respondidos, na tentativa de amenizar erros de interpretação por parte dos alunos. Foram consideradas corretas as respostas dadas segundo a teoria científica sobre o assunto e utilizamos a teoria científica como referência para a posterior análise das respostas dos alunos aos questionários.

\section{V.5.2 Análise das respostas dos questionários}

Os resultados dessa primeira avaliação mostraram que houve mais êxito dos alunos em responder as questões que se referiam aos experimentos mostrados na exposição. Além disso, as questões sobre temas do cotidiano mais acertadas abordavam a teoria cinética dos gases.

A teoria cinética foi explicada em dois experimentos, sendo que num deles os alunos puderam ver um modelo do que acontecia com as moléculas do gás. O tópico apresentado em maiores detalhes, com experimentos eficientes, proporcionam melhores resultados. A questão 1 do segundo questionário não exigia a explicação do comportamento das moléculas do ar na transformação gasosa; mesmo assim, na maioria das respostas os alunos tentaram explicar o fato. Isso mostra que a exposição sobre a teoria cinética dos gases, juntamente com a explicação do monitor, propiciou um aprimoramento da linguagem dos alunos ao abordar o fenômeno físico. 
Os piores resultados nos chamaram a atenção para que alguns temas fossem mais bem explicados. Um exemplo é o fenômeno da troca de calor. Na exposição falou-se apenas da convecção e isso comprometeu o bom rendimento dos alunos. Outro assunto pouco compreendido pelos alunos foi o das máquinas térmicas. Mais experimentos, recursos gráficos, ou até uma mudança no roteiro das explicações, poderiam melhorar os resultados da avaliação. É claro que isso não poderia ser feito sem uma prévia discussão dos objetivos da exposição junto ao público.

\section{V.5.3 Entrevistas da segunda etapa de avaliação}

Estas entrevistas foram realizadas no dia 27 de abril de 2000, com dezessete alunos de ensino médio que participaram da exposição no dia 22 de março, totalizando oito entrevistas com diferentes grupos.

As entrevistas ocorreram com os alunos sentados diante de uma mesa, onde o entrevistador colocou as fotos de todos os experimentos que foram demonstrados na exposição.

Primeiramente foi mostrada aos alunos a foto da experiência da bexiga, e o entrevistador perguntava se os alunos se lembravam o que acontecia.

Ficou evidente nas respostas dos alunos, que a diminuição do volume do ar dentro da bexiga estava associada à diminuição de sua temperatura, mesmo sem utilizar toda a formalidade da teoria cinética dos gases. Nem mesmo as palavras temperatura e volume foram citadas. Uma das coisas que mais chamaram a atenção dos alunos na exposição foi a "fumaça" que saia do tambor de nitrogênio líquido. Desde o primeiro momento da visita ficou claro para os alunos que a temperatura do nitrogênio líquido era $-196^{\circ} \mathrm{C}$. O aluno pode não memorizar as palavras, mas entende o fenômeno físico. Essa é uma característica do ensino informal.

Um detalhe sobre as respostas é que o conceito de pressão não foi citado pelos alunos. Isso é um indício do nível de compreensão da teoria e das limitações da exposição. A causa para que a bexiga murchasse era a diminuição do volume de ar. Mas a redução do volume é um efeito direto da queda da temperatura e da pressão dentro da bexiga. Não foram considerados os detalhes da explicação, por parte dos alunos, que incluíam o conceito de pressão. Concluímos então que a exposição não foi eficiente em demonstrar esse conceito. A situação, que estava bem definida para o professor, não ficou clara para os alunos.

Além disso, não há diferença para os alunos entre os conceitos de pressão e temperatura no modelo apresentado na exposição. Na entrevista com alunos diferentes, foi feita a pergunta sobre como eles poderiam explicar o conceito de pressão a partir do experimento da teoria cinética dos gases. Não houve resposta em nenhuma das entrevistas.

Os alunos se sentiram satisfeitos em explicar o experimento da bexiga, utilizando apenas os conceitos de volume e temperatura. Não houve intenção em explicar mais detalhes sobre as causas do fenômeno.

Mencionamos também nas entrevistas o experimento que ilustra o conceito de convecção: o experimento dos dois canecões. Perguntamos para todos alunos inicialmente se conheciam como o experimento funcionava. Todas as respostas foram afirmativas no sentido de conhecer o experi- mento e explicá-lo. Todos os alunos souberam dizer o que acontecia. A água quente e a água fria em movimento até que ficassem com a mesma temperatura. Água quente pelo caminho de cima e a água fria pelo caminho de baixo.

Reconheceram o termômetro e o ebulidor. A maioria dos alunos também sabia que a temperatura da água em um dos canecões aumentava até um limite de aproximadamente 98 ${ }^{o} \mathrm{C}$, enquanto a rolha tampava um dos caninhos. E um dos alunos disse esse fenômeno era devido à transformação da água líquida em vapor. Poucos alunos souberam denominar o fenômeno de troca de calor como convecção.

Os outros experimentos, como o anel de s'Gravezande, a locomotiva, e a Eolípila de Herón, foram algumas vezes citados pelos alunos como o experimento que mais gostaram. Não houve dificuldades para os alunos em explicar esses experimentos informalmente. Com exceção do anel de s'Gravezande, que alguns alunos tiveram dúvidas sobre como a esfera poderia dilatar, e a locomotiva, que os alunos tiveram dificuldade de explicar detalhes de seu mecanismo de funcionamento. Em relação à locomotiva, somente um aluno deu mais detalhes sobre o mecanismo de funcionamento.

Não fizemos muitas perguntas aos alunos sobre máquinas térmicas. Acreditamos que a exposição não ofereceu condições para tanto, em relação ao tempo da exposição e também aos recursos utilizados pelo monitor para explicar o funcionamento da locomotiva.

\section{V.5.4 Terceira etapa das entrevistas: a avaliação da com- preensão do modelo da teoria cinética dos gases através de sua aplicação num programa computacional}

Nos dias 13 e 14 e 15 de julho de 2000, foram realizadas entrevistas com alunos do ensino médio sobre um programa de computador chamado Movimento Browniano, criado por Luís Paulo Piassi para o projeto Interage (www.scite.pro.br).

$\mathrm{Na}$ tela do programa são visualizadas as moléculas de água colidindo com uma minúscula partícula de pólen. Aciona-se uma determinada tecla e as moléculas desaparecem. Na tela estaria o pólen se movimentando dentro de um quadro. Ele ricocheteia na parede e muda de direção aleatoriamente no meio do caminho, sem uma causa aparente para que isso aconteça. Quando a tecla com o nome moléculas é acionada, as moléculas de água entram em cena possibilitando a visualização da causa do movimento do pólen.

O objetivo da atividade com esse programa de computador foi a verificação da possibilidade dos alunos conseguirem descobrir porque o pólen se movimenta dentro do quadro, que representa uma porção de água. A atividade deve ser muito bem explicada. Utilizamos até um dicionário, para que o aluno não tivesse nenhuma dúvida sobre o significado de algumas palavras que fossem eventualmente desconhecidas.

Num microscópio de pesquisa escolar ao lado do computador, colocamos uma pequena porção de água, mais ou menos duas gotas, numa lâmina de vidro para que uma micro partícula de pólen boiasse sobre a mesma. Transcrevemos abaixo o diálogo do entrevistador com os alunos:

- "Olhe para o computador e imagine que você está vendo a imagem gerada pelo microscópio, igual a este aqui 
ao lado. Você estaria enxergando através das lentes do microscópio uma minúscula partícula de pólen se movimentar aleatoriamente sobre a água. Observe que a água que foi colocada em cima desta lâmina no microscópio ao lado. Não há mais que duas gotas de água aqui. A água está quente como a que sai de um chuveiro ligado na posição inverno, por exemplo. O pólen é bem leve e flutua sobre a água. Estamos fazendo de conta que você está enxergando o movimento do pólen sobre a água no microscópio nessa tela do computador. Nesse momento o entrevistador aponta para o circulo esverdeado que representa o pólen, assim como para a região da tela onde estaria a água”.

Algumas dúvidas surgiram por parte dos alunos, mas não encontramos dificuldades solucioná-las rapidamente.

Depois da explicação, perguntamos ao aluno:

- Você pode explicar a causa desse movimento?

As respostas dos alunos, na maioria das vezes, foram bem curtas. Diziam apenas que não sabiam. De 20 alunos entrevistados apenas dois responderam à pergunta, associando a resposta à lembrança do modelo da teoria cinética dos gases apresentado na exposição. Um outro aluno chegou a dizer que era uma coisa que batia no pólen e gerava o movimento, mas não lembrava o nome. Os outros 17 alunos nem sequer tentaram responder.

Devemos analisar em cada tipo de avaliação os resultados obtidos. Do ponto de vista da segunda avaliação, a exposição valeu a pena em seus aspectos cognitivos. Se levarmos em conta porém a última avaliação, a exposição não obteve sucesso em seus propósitos. Poderíamos concluir a partir disso que o ensino informal não traz grandes benefícios ao aluno para responder a problemas práticos? Afinal de contas eles se deram bem apenas diante da avaliação feita a partir dos experimentos que já haviam visto. Numa situação, onde a boa compreensão da teoria poderia levar uma resposta correta, os alunos não obtiveram sucesso. A capacidade de solucionar um problema inédito seria, dentro das concepções de Vigotski, a melhor forma de avaliar a compreensão da teoria. Então nesse ponto de vista a exposição obteve sucesso em $15 \%$, de acordo com a montagem que utilizamos.

Outro ponto de vista que deve ser levado em consideração é o fato da situação da avaliação não ter ficado clara para os alunos. A explicação não foi compreendida. Seu conteúdo poderia estar fora da zona de desenvolvimento proximal dos alunos. A situação não foi elucidada de maneira clara para que pudesse ser dada uma resposta sobre ela. Essa versão não prejudicaria o conhecimento adquirido na exposição e sim a avaliação. Na apresentação do problema o entrevistador fala numa partícula suspensa num líquido quente, não num gás quente. Nós sabemos que o fenômeno físico é praticamente o mesmo para o movimento browniano observado num líquido ou gás, mas os alunos não sabem disso. O exemplo que eles poderiam utilizar para responder à pergunta (a exposição) falava de um gás e não de um líquido. Para definir melhor a situação, o entrevistador poderia ter falado mais sobre a exposição para quem não conseguiu dar nenhuma resposta.

\section{Conclusão}

Todas os testes da última pesquisa apontaram para uma grande dificuldade dos alunos: utilizar a teoria vista na exposição em situações novas, diferentes daquelas observadas durante as demonstrações. As mesmas considerações valem para as entrevistas realizadas com a ajuda do software educacional. Uma situação real foi apresentada para que os alunos aplicassem os conceitos que viram na exposição. Houve um baixo índice de acertos.

Inúmeras situações do cotidiano poderiam ser apresentadas para que os alunos tentassem utilizar o modelo teórico visto na exposição. O êxito nas respostas dependeria dos alunos enxergarem as situações apresentadas como um sistema específico entre muitos outros; o que leva à consciência de suas operações.

Esse ideal de aprendizagem de modelos científicos poderia ser alcançado depois de sucessivas ações de ensino. Por meio de outros experimentos sobre o mesmo assunto, ou de outros recursos didáticos como a computação, vídeos, debates, entre outros. A exposição apresentada não possuía tantos recursos sobre um só tema, mas trabalhava com uma infinidade deles. Portanto não está ao alcance de uma exposição científica, como a descrita nesse trabalho, levar um aluno de ensino médio a formas elevadas de compreensão de um modelo científico.

Apesar disso, a exposição contribuiu para o inicio de um desenvolvimento cognitivo. Na escola os alunos poderiam rever o conteúdo inicialmente abordado nas exposições. O professor poderia fazer uso de outros recursos para explicar melhor os modelos científicos e introduzir os alunos ao aprendizado dos conceitos científicos vinculados à exposição. Nas palavras de Vigotski: "A disciplina formal dos conceitos científicos transforma gradualmente a estrutura dos conceitos espontâneos da criança e ajuda a organiza-los num sistema; isso promove a ascensão da criança para níveis mais elevados de desenvolvimento" [Vigotski, 1987]. O estudo de conceitos científicos como temperatura e pressão, por exemplo, inseridos no modelo utilizado para explicar alguns experimentos, podem ser abstraídos tendo como referência uma situação concreta, facilitando a aprendizagem.

As visitas a museus de ciência poderiam fazer parte do currículo escolar como um complemento ao ensino formal, já que as exposições científicas não são levadas às escolas. Os museus de ciência são ambientes de enriquecimento cultural de grande potencial a ser aproveitado pelos professores. O artigo de Janette Griffin e David Symington [Griffin e Symington, 1997] discute a importância de se vincular as visitas aos museus de ciência aos programas escolares. Esse trabalho nos mostra que pouco se faz nesse sentido, e que isso está diretamente relacionado à aprendizagem e ao interesse dos alunos pelo conteúdo das exposições. Os autores de outro artigo vão mais além, ao dizer que a aprendizagem dos conceitos abordados pelas exposições só se consolida fora dos museus [Anderson, Lucas, Ginns e Dierking, 2000].

Por outro lado, muitos alunos se saíram bem nos testes e entrevistas. Mas as respostas corretas não podem 
ser usadas como diagnóstico de que determinado aluno domina o conteúdo da exposição. A aprendizagem dos modelos científicos é um processo longo que não termina com a exposição. $\mathrm{O}$ aluno pode ter usado a linguagem corretamente para dar uma resposta, sem possuir domínio dos conceitos abordados nas explicações dos experimentos. Tivemos como objetivo ao aplicar questionários e realizar entrevistas, demonstrar que a exposição cumpriu com seu papel de iniciar ou reforçar processos de aquisição de conhecimentos em termodinâmica nos alunos.

Em relação às respostas corretas, de uma maneira geral, os alunos obtiveram mais sucesso quando o assunto foi a Teoria Cinética dos Gases. Quando o assunto das perguntas dos questionários ou entrevistas era o conteúdo de experimentos como a locomotiva por exemplo, os resultados não chegaram a mostrar respostas corretas ao menos na descrição dos mesmos. Isso se deve, em parte, à falta de uma explicação mais detalhada e abundante de recursos materiais. Esses experimentos cognitivamente mais pobres poderiam ser objeto de estudos posteriores em que fossem investigados individualmente. Muitos trabalhos em museus de ciência têm como objeto de estudo um único experimento ou exposições com até três experimentos [Borun, Massey e Lutter, 1993], [Roth, McRobbie, Lucas e Boutonné, 1997], [Falk, 1997], [Allen, 1997].

Vale lembrar também a importância dos monitores na exposição. A linguagem das respostas dos testes e entrevistas foi veiculada pelo monitor, sem o qual não se completaria o processo ensino-aprendizagem dos experimentos. Pode-se verificar isso, comparando o nível das respostas dos testes dadas antes e depois da exposição. A influência do discurso do monitor nas respostas dadas depois da visita é significativa. Gostaríamos de reforçar aqui a importância do treinamento dos monitores num museu de ciências, principio ao qual está amarrado o sucesso das exposições.

A segunda exposição foi montada de acordo com um diagnóstico que apontou erros no discurso dos monitores da Estação Ciência na pesquisa-piloto. A primeira pesquisa também foi útil para mostrar que o método de análise da aprendizagem era deficiente e poderia ser melhorado.

Os resultados da análise das respostas dos questionários e entrevistas da segunda exposição também podem servir de diagnóstico para a elaboração de outra exposição de termodinâmica. Esta exposição fictícia teria como referência às deficiências e acertos da segunda, que foram apontados nas entrevistas e nos questionários. A conclusão dos trabalhos dessa pesquisa não indica que está tudo acabado, mas que ainda há muito que fazer. Com a montagem de uma nova exposição, levando-se em consideração os resultados dessa pesquisa, poderíamos realizar um trabalho mais completo de divulgação cientifica em termodinâmica e avaliação.

Um artigo de Ramey-Gassert et al. [Ramey-Gassert et al., 1994] sugere que a avaliação em museus deve buscar informações sobre comportamento e interesse dos visitantes, bem como da capacidade de comunicação das exposições, buscando mudanças, se necessário. Avaliações podem ser formativas ou somativas. As avaliações formativas visam o aprimoramento do design das exposições pela observação das reações dos visitantes, seguindo alguns procedimentos: a) preparação dos modelos; b) observação e teste das reações dos visitantes para comparação com possíveis expectativas ou metas; c) ajuste dos modelos; d) reteste dos modelos e e) incorporar o modelo bem sucedido para o design final. [Ramey-Gassert et al., 1994]

Ainda segundo Ramey-Gassert et al., a avaliação somativa ocorre depois que a exposição está pronta. Como as pessoas estão interagindo com a exposição, o que estão aprendendo e se o conteúdo da exposição está sendo aproveitado na escola ou no cotidiano dos visitantes; são alguns objetivos da avaliação somativa. A aplicação da avaliação somativa se dá através da observação da atenção dos visitantes na exposição, entrevistas, questionários e outras técnicas. [Ramey-Gassert et al., 1994]

Podemos concluir que a exposição evoluiu bastante da primeira para a segunda pesquisa. Mas, para que a exposição de termodinâmica fizesse parte de um museu, ela necessitaria de uma nova reformulação. E, de tempos em tempos, novos testes deveriam ser aplicados para que a exposição fosse sempre atualizada, num processo de avaliação contínua.

\section{Referências}

[1] TEIXEIRA, O.P.B.- Desenvolvimento do conceito de calor e temperatura, São Paulo, tese de doutorado (FEUSP,1992).

[2] SILVA, D.- Estudo das trajetórias cognitivas de alunos no ensino da diferenciação dos conceitos de calor e temperatura, São Paulo, tese de doutorado (FEUSP, 1995).

[3] SILVEIRA, F.L.; MOREIRA, M.A.- Validacion de un test para verificar si el alumno posee concepciones cientificas sobre calor, temperatura y energia interna, Revista Ensenãnza de las Ciencias, Barcelona, 14(1), pp.75-86 (1996).

[4] GASPAR, A.- Museus e Centros de Ciências - Conceituação e Proposta de um Referencial Teórico, São Paulo, tese de doutorado (FEUSP, 1993).

[5] LEWIS, D.G.- Análise de Variância, Ed.Harbra (1995).

[6] VYGOTSKY, L.S.- Pensamento e linguagem, Ed. Martins Fontes (1987).

[7] BORUN, M.; MASSEY, C.; LUTTER, T.- Naive knowledge and the design of science museum exhibits, Curator, 36/3, pp. 201-219 (1993).

[8] GOUVEIA, G.; MARANDINO, M.- Paradigmas em exposições de museus de ciência e tecnologia, Atas do VI EPEF, Florianópolis (1998).

[9] CRONBACH, Lee J.- Coeficient Alpha and the internal structure of tests, Psycometrica, 16(3), pp. 297-334 (1951).

[10] Parâmetros Curriculares Nacionais / Ensino Médio - MEC

[11] Proposta curricular para o ensino de física 2o Grau, Secretaria de Estado da Educação - CENP, São Paulo (1992).

[12] GASPAR, A.; HAMBURGER, E. W.- Museus e centros de ciências - conceituação e proposta de um referencial teóricoIn: NARDI, R., org..- Pesquisas em ensino de Física, Ed. Escrituras, São Paulo (1998).

[13] Projecto física, Unidade 3, Fundação Calouste Gulbenkian.

[14] Leituras de física (versão preliminar), Física Térmica, GREF. 
[15] FALK, John H.- Testing a museum exhibition design assumption: Effect of explicit labeling of exhibit clusters on visitor concept development, Science Education,81, pp. 679-687 (1997).

[16] CAZELLI, S. et. al.- Aprendizagem em museus de ciências e tecnologia sob o enfoque dos modelos mentais, Atas do VI EPEF, Florianópolis (1998).

[17] FALK, J.H.; MOUSSOURI, T.; COULSON, D.- The efect of visitors' agendas on museum learning, Curator, , 41(2), pp.107-121 (1995).

[18] ASTC (Association of Science and Tecnology Centers) What Research Says about Learning in Science Museums (1990).

[19] GRIFFIN, J.; SYMINGTON, D.- Moving from TaskOriented to Learning-Oriented Strategies on School Excursions to Museums, Science Education, pp. 763-779 (1997).
[20] ANDERSON, D.; LUCAS, K. B.; GINNS, I. S.; DIERKING, L. D. - Development of Knowledge about Electricity and Magnetism during a Visit to a Science Museum and Related Post-Visit Activities, Science Education, pp. 658-679 (2000).

[21] SHEPARDSON, D. P. - Learning Science in a First Grade Science Activity: A Vygotskian Perspective, Science Education, pp. 621-638 (1999).

[22] ALLEN, S. - Using Scientific Inquiry Activities in Exhibit Explanations, Science Education, pp. $717-734$ (1997).

[23] MAURÍCIO, L. A. - Centros de Ciências: Origens e Desenvolvimento - uma Reflexão sobre o seu Papel e Possibilidades dentro do Contexto Educacional, São Paulo, dissertação de mestrado(IF/FEUSP,1992). 